\title{
Devemos Mudar os Valores de Referência para TSH Normal?
}

$\mathrm{O}$ S NÍVEIS DE REFERÊNCIA PARA NORMALIDADE são fundamentais para a própria validação de um teste como método diagnóstico, além de serem essenciais para a tomada de decisão terapêutica. Como se obtêm esses valores de referência? O que é normal, por conceito, é o que predomina em uma grande população saudável. Assim, os níveis de normalidade do ensaio de TSH são obtidos por meio da média do valor de TSH com um intervalo de confiança de 95\%, em uma população supostamente sem doenças tireoidianas. Entretanto, uma série de observações recentes sugere que os indivíduos que apresentam valores nos níveis atualmente considerados limites superiores da normalidade não são normais, mas, em verdade, possuem uma disfunção tireoidiana mínima (1). Esses indivíduos estariam "puxando" os valores considerados normais do TSH para cima.

O limite superior de normalidade varia muito em diferentes populações: entre 2,4 e 4,2 mIU/L. Grandes estudos, como o NHANES III, que utilizaram os dados de 13.344 pessoas e excluíram indivíduos com histórias de doenças da tireóide, bócio, uso de medicamentos que influem na avaliação tireoidiana, grávidas e indivíduos com anticorpos antitireoidianos positivos, mostram limites superiores de TSH em torno de 4,2 $\mathrm{mIU} / \mathrm{L}$ para a população branca e de 3,6 mIU/L para a população negra com anticorpos antitireoidianos negativos (2). A média do TSH situou-se em 1,39 mIU/L (2).

No entanto, cerca de $20 \%$ dos indivíduos com pequenas elevações de TSH, sinais ultra-sonográficos e achados citológicos sugestivos de tireoidite, como a característica infiltração linfocitária, não possuem níveis circulantes de anticorpos antitireoidianos detectáveis (3). Os níveis de TSH elevam-se em faixas etárias mais avançadas nas quais também aumenta a incidência de tireoidites auto-imunes. Além disso, em idades mais avançadas, aumenta a presença de nódulos na glândula, assim como a possibilidade de nódulos autônomos ficarem tóxicos. A American Association of Clinical Endocrinologists, levando em conta os níveis de TSH menos associados à presença de AcTPO em homens e mulheres, considera que o valor superior de normalidade deve ser de $3 \mathrm{mIU} / \mathrm{L}$, que se assemelha ao valor de 2,5 mIU/L sugerido pela Endocrine Society. TSH?

Será que deveríamos mesmo mudar os valores de referência do ensaio de

O perigo que reside em diminuirmos os valores máximos de referência é de sermos induzidos a tratar de hipotireoidismo subclínico mais indivíduos com valores pouco elevados de TSH.

Claro que o exame clínico e a história do paciente, assim como a validação de outras comorbidades, dislipidemia em particular e outros fatores de risco devem ser cuidadosamente avaliados antes de se indicar um tratamento cujo benefício ainda é discutível. Mas também é importante lembrar que dos 820

\section{carta ao editor}

\author{
LAURA Sterian Ward
}

Faculdade de Ciências Médicas da Universidade Estadual de Campinas (FCM-Unicamp), SP, Brasil. 
indivíduos em uso de medicação para hipertireoidismo do estudo do NHANES III, 18,3\% possuíam evidência de hipertireoidismo (7,3\% clínico, 10,9\% subclínico) (2). Pacientes que são atendidos a nível hospitalar freqüentemente possuem uma causa, que não a doença tireoidiana progressiva, para apresentar TSH borderline (4). No estudo do Colorado, $40 \%$ dos indivíduos em uso de hormônios tireoidianos apresentavam níveis de TSH menores do que $0,3 \mathrm{mIU} / \mathrm{L})$, e o recente estudo do grupo da Universidade Federal do Rio de Janeiro (UFRJ) sugerem que esses números não são diferentes no Brasil. Mais ainda, em nosso meio, cerca de $20 \%$ dos pacientes em uso de levotiroxina correm o risco de desenvolver importantes efeitos cardiovasculares por prescrição de dosagens excessivas (5).

Em conclusão, independentemente do valor de referência que o TSH possa ter, a clínica continua sendo soberana na decisão terapêutica, e a observação cautelosa, nossa melhor amiga.

\section{REFERÊNCIAS}

1. Spencer CA, Hollowell JG, Kazarosyan M, Braverman LE. NHANES III TSH: TPOAb relationships demonstrate that TSH upper reference limits may be skewed by occult thyroid dysfunction. J Clin Endocrinol Metab. 2007; [Epub ahead of print].

2. Hollowell JG, Staehling NW, Flanders WD, Hannon WH, Gunter EW, Spencer CA, et al. Serum TSH, T(4), and thyroid antibodies in the United States population (1988 to 1994): National Health and Nutrition Examination Survey (NHANES III). J Clin Endocrinol Metab. 2002;87:489-99.

3. Vejbjerg P, Knudsen N, Perrild H, Laurberg P, Pedersen IB, Rasmussen LB, et al. The association between hypoechogenicity or irregular echo pattern at thyroid ultrasonography and thyroid function in the general population. Eur $\mathrm{J}$ Endocrinol. 2006;155:547-52.

4. Ward LS, LC Oliveira, A de O Santos, G d'A Fernandes. Avaliação clínica de um ensaio sensível de TSH na definição do estado tiroidiano. Arq Bras Endo Metab. 1995;32:12-6.

5. Bagattoli RM, Vaisman M, Lima JS, Ward LS. Estudo de adesão ao Tratamento do Hipotiroidismo. Arq Bras Endo Metab. 2000;44:483-7.

\section{Endereço para correspondência:}

Laura S. Ward

Rua Tessália Vieira de Camargo, 162

13081-970 Campinas, SP

E-mail: ward@unicamp.br 